\title{
PSCAD/EMTDC-Based Modeling and Simulation of Three-terminal VSC-HVDC System
}

\author{
Hu Hao ${ }^{1, a}$, Liu Yang ${ }^{1}$, Long Rishang ${ }^{1}$, Tan Tao', Meng Yuan ${ }^{1}$, Zhang \\ Jianhua ${ }^{1}$, Xu Yunfei ${ }^{2}$, Jin Guofeng ${ }^{2}$, \\ ${ }^{1}$ State Key Laboratory of new energy power system, North China Electric Power University, Beijing, \\ China, 102206 \\ ${ }^{2}$ Inner Mongolia Eastern Electric Power Co., Ltd. Economic and Technical Research Institute, Inner \\ Mongolia, China, 010010 \\ ahuhao_o@126.com
}

Keywords: AC-DC hybrid power grid, Multiport VSC-HVDC System, Control strategy

Abstract. For further study on the principle and characteristics of multi-terminal VSC-HVDC system under the condition of the AC/DC hybrid power grid, firstly, this paper establishes the model of three-terminal VSC-HVDC system based on PSCAD/EMTDC. Secondly, according to the different transmission properties between the different terminals, the suitable control strategy for each terminal is proposed. Finally, -simulation and analysis under the steady-state and faulted scenarios are presented. The results show that multi-terminal VSC-HVDC system has many advantages, such as better controllability, relatively strong independence between different terminals, etc. And the multi-terminal VSC-HVDC system has good prospects for development.

\section{Introduction}

At the end of 1990s, voltage source converters (VSC) based on self-turn-off valves and pulse width modulation (PWM) technologies were applied to HVDC system, which marked the birth of the third generation of HVDC technology. The Conference International des Grands Reseaux Electriques (CIGRE) which is the international authoritative academic organization and the American institute of electrical and electronic engineers (IEEE) named it as VSC-HVDC officially. The ABB called it HVDC Light, and the Siemens called it HVDC Plus. But the scholars in China were named it as Flexible HVDC uniformly ${ }^{[1]}$. In this paper, we adopt VSC-HVDC for discussion.

In China, the research and application of the traditional HVDC technology has been very thorough and mature. And there are many HVDC projects which are widely practiced. However, there are still so many problems in the practical application. For instance, the traditional HVDC systems can not supply power for passive power grid and are prone to commutation failure when severe fault occurs ${ }^{[2]}$. Because of the self-turn-off characteristic of IGBT, the VSC-HVDC system has been an effective method to solve the defect of traditional HVDC at above aspects. The VSC-HVDC system realizes the power supply from the DC system to the passive power grid and is not prone to communication. The VSC-HVDC system has flexible operation modes and better controllability. In addition, the VSC-HVDC system has very obvious advantages on the application to weak power systems, island power supply, and the grid connection of distributed generation

For the past few years, because of above-mentioned advantages, many scholars have studied so much on multi-terminal VSC-HVDC system. References [3-7] establish the mathematical model of VSC-HVDC and introduce its control strategy. References [8-10] introduce the control strategy of multi-terminal VSC-HVDC system and its simulation study. References [11-13] introduce the control strategy of VSC-HVDC system which supplies power to passive power grid. References [14] introduce the DC voltage characteristics and protection strategy when the VSC-HVDC system is under the fault condition.

In this paper, firstly the model of the three-terminal VSC-HVDC system is established. Then, the selection and design of different kinds of controllers are analyzed, and the control characteristics under 
varying loads are discussed. Lastly, the single-phase grounding fault and three-phase short-circuit fault are simulated and analyzed.

\section{Operational principle of the VSC-HVDC system}

The main circuit structure of VSC is showed in Fig. 1. The VSC is made up of six bridge arms and every bridge arm is made up of one self-turn-off valve IGBT and one backward diode in parallel connection. The three-phase bridge arm of every converter has double groups of IGBTs. And the above group and the below one turn on or off alternately. This way makes every phase of AC side can be connected with positive pole or negative pole of DC side. On every phase of the bridge arm, the double groups of IGBTs' on-off state are complementary to each other all the time.

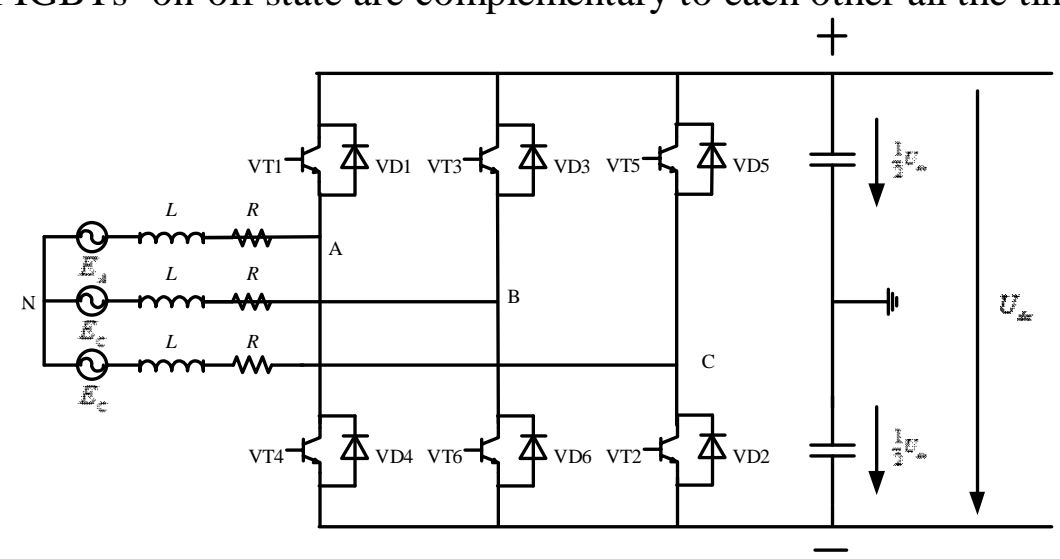

Fig. 1 The main circuit structure of VSC

Where $E_{A}, E_{B}$ and $E_{C}$ are the electromotive force of grid in the AC side, $L$ is the filter inductor on the AC side, $R$ is the equivalent resistance of the transformer and converter, VT1 VT6 are the IGBTs, VD1 VD6 are the shunt capacitors, $U_{d c}$ is the voltage between positive pole and negative pole on the DC side.

In the steady state, $E_{A}, E_{B}$ and $E_{C}$ change to $E_{d}$ and $E_{q}$ after the d-q transform, and the mathematical model can be described as the following formulas:

$$
\begin{aligned}
& E_{d}=L \frac{\mathrm{d} i_{d}}{\mathrm{~d} t}+R i_{d}+u_{d}+\omega L i_{q} \\
& E_{q}=L \frac{\mathrm{d} i_{q}}{\mathrm{~d} t}+R i_{q}+u_{q}-\omega L i_{q} \\
& U_{d c} i_{d c}=\frac{3}{2}\left(u_{d} i_{d}+u_{q} i_{q}\right)
\end{aligned}
$$

where $E_{d}$ and $E_{q}$ are the $\mathrm{d}$ and q decoupling components of $E_{A}, E_{B}$ and $E_{C}$ (the electromotive force of grid in the AC side), $u_{d}$ and $u_{q}$ are the $\mathrm{d}$ and q decoupling components of three-phase VSC voltage on the AC side, $i_{d}$ and $i_{q}$ are the d and q decoupling components of three-phase VSC current on the AC side.

We make $\mathrm{d}$ axes coincides with the voltage vector, so that $u_{d}=E_{d}$ and $u_{q}=0$. And we assume the loss of transformer and converter can be ignored, so that is $R=0$. The expressions of active and reactive power injected from AC system to the converter station are as follows

$$
\begin{aligned}
& P=\frac{3}{2}\left(u_{d} i_{d}+u_{q} i_{q}\right)=\frac{3}{2} u_{d} i_{d} \\
& Q=\frac{3}{2}\left(u_{d} i_{q}-u_{q} i_{d}\right)=\frac{3}{2} u_{d} i_{q}
\end{aligned}
$$


According to the equation (4) and (5), it is obvious that $P$ is just controlled by $i_{d}$ and $Q$ is just controlled by $i_{q}$. By controlling the $i_{d}$ and $i_{q}$ on the AC side, the decoupling control of active and reactive power can be realized between the $\mathrm{AC}$ system and converter.

\section{Study of the control strategy}

\section{Introduce of the basic control strategy}

This paper discusses that two active power grid supply power to a passive power grid. The active power grid simulates the bulk power grid and adopts constant DC voltage control and constant reactive power control. The other one simulates a distributed generation (e.g. wind park) and adopts constant active power control and constant reactive power control. The passive power grid simulates passive load in remote areas and adopts constant AC voltage control.

\section{Design of the controller}

The VSC1 on the rectifier side adopts constant DC voltage control and constant reactive power control. The control block diagram is shown in Fig. 2.

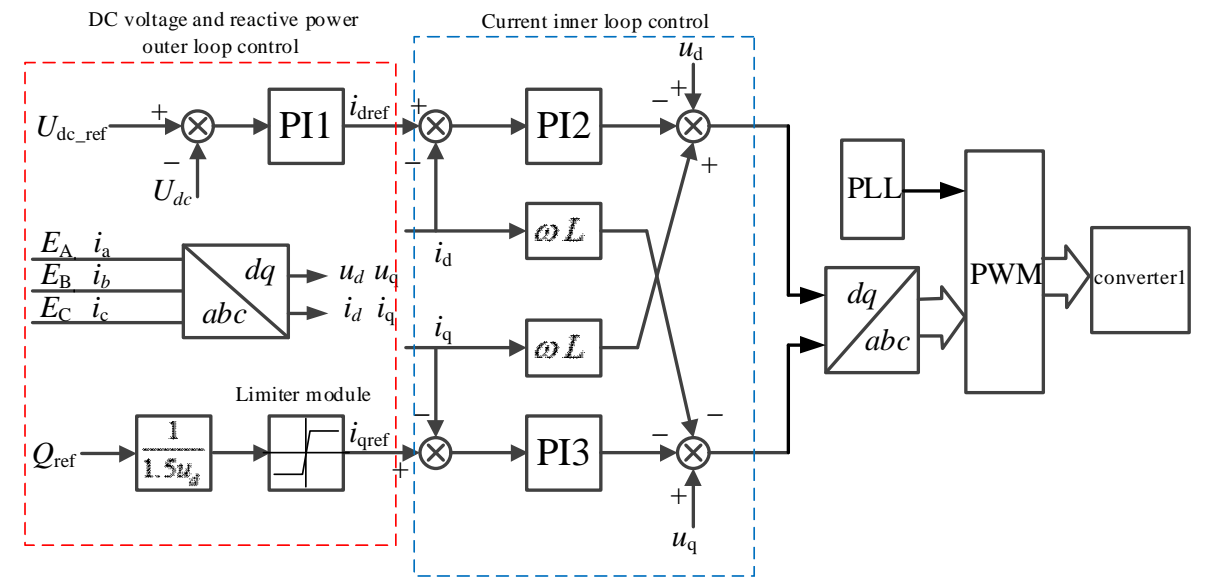

Figure 1 The control block diagram of VSC1

In the control block of VSC1, the proportionality coefficient $K_{P}=0.05$ and the integration coefficient $T_{i}=1.1$ in controller PI1, the proportionality coefficient $K_{P}=60$ and the integration coefficient $T_{i}=0.0002$ in controller PI2 and the proportionality coefficient $K_{P}=60$ and the integration coefficient $T_{i}=0.0002$ in controller PI3. The reference voltage of the DC side is $500 \mathrm{kV}$.

The VSC2 on the rectifier side adopts constant active power control and constant reactive power control. The ontrol block diagram is shown as in Fig. 3.

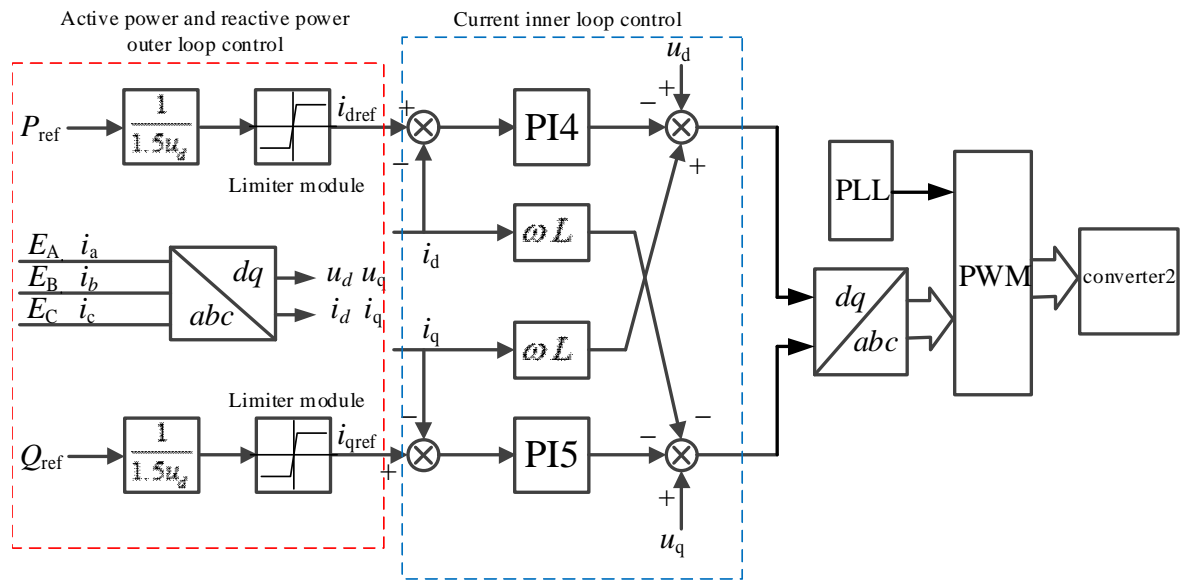

Figure 2 The control block diagram of VSC2 
In Fig. 3, the proportionality coefficient $K_{P}=60$ and the integration coefficient $T_{i}=0.0002$ in controller PI4 and the proportionality coefficient $K_{P}=60$ and the integration coefficient $T_{i}=0.0002$ in controller PI5. The active power reference is 100MW. The reactive power reference is 20MVar.

The VSC3 on the inverter side adopts constant DC voltage control and its control block diagram is shown in Fig. 4.

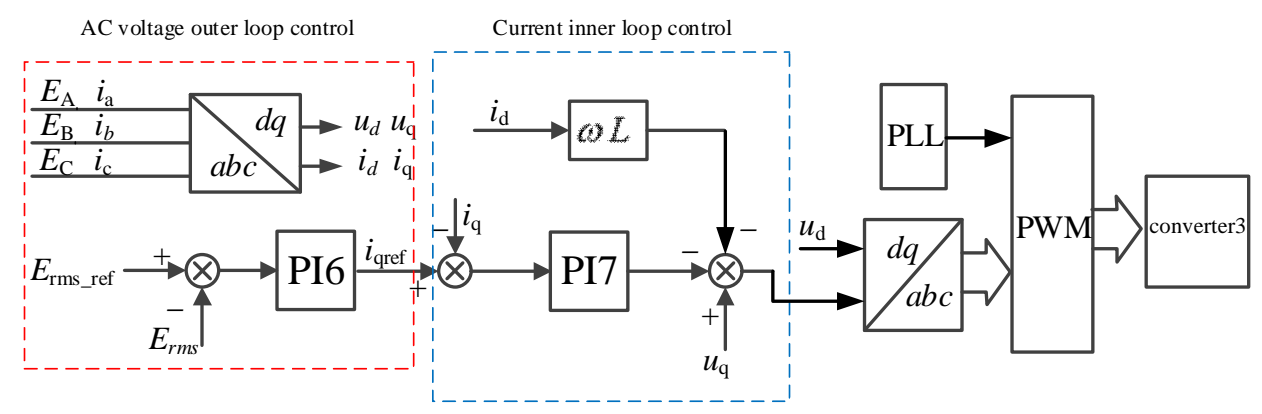

Figure 3 The control block diagram of VSC3

In the control block of VSC2, the proportionality coefficient $K_{P}=10$ and the integration coefficient $T_{i}=0.005$ in controller PI6, the proportionality coefficient $K_{P}=60$ and the integration coefficient $T_{i}=0.0002$ in controller PI7. The AC voltage reference is $500 \mathrm{kV}$.

\section{Simulation example and analysis}

\section{Establishing the system simulation model}

This paper establishes the model of a three-terminal VSC-HVDC system. The three terminal adopt parallel connection as in Fig. 5.

The VSC1 on the rectifier side connects to the bulk power grid. Its AC voltage is $420 \mathrm{kV}$ and its frequency is $60 \mathrm{~Hz}$. The VSC2 on the rectifier side connects to the wind park. Its AC voltage is $420 \mathrm{kV}$ and its frequency is $50 \mathrm{~Hz}$. The VSC3 on the inverter side connects to the bulk power grid. Its AC voltage is $500 \mathrm{kV}$ and its frequency is $50 \mathrm{~Hz}$.In the DC side, the voltage is $500 \mathrm{kV}$, the resistance is $14 \Omega$, the inductance is $1.1936 \mathrm{H}$ and the capacitance is $52 \mu F$.

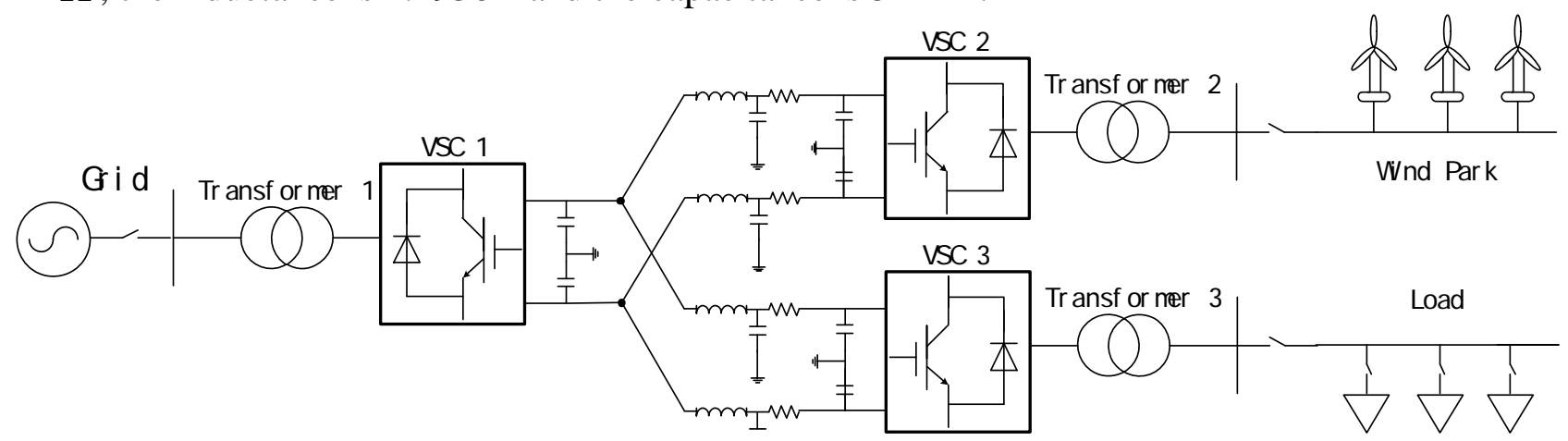

\section{Simulation results}

Figure 4 Three-terminal VSC-HVDC system

\section{Variable load simulation in the steady state}

The initial load of VSC3 is $200 \mathrm{MW}+40 \mathrm{MVar}$ (resistance-inductance load). The simulation system enters a steady state after $1 \mathrm{~s}$. The load of VSC3 changes to $300 \mathrm{MW}+60 \mathrm{MV}$ ar when the time is $2 \mathrm{~s}$ and changes back into 200MW+40MVar when the time is 4s. The electrical parameters' change of VSC1, VSC2 and VSC3 on the AC and DC sides are showen in Fig. $6 \sim$ Fig. 8. 


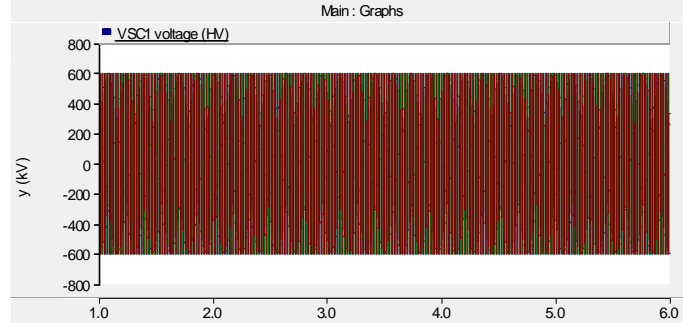

a) AC voltage

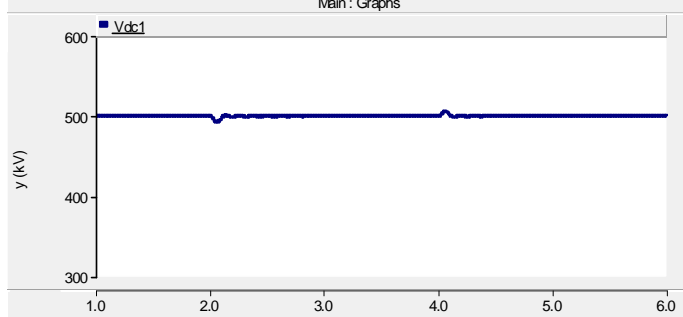

c) DC voltage

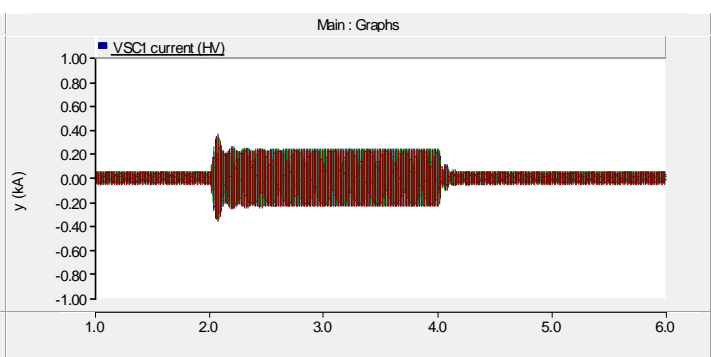

b) AC current

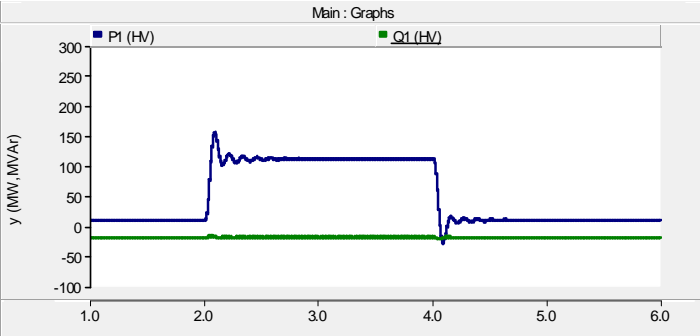

d) Active power and reactive power

Figure 6 AC voltage, AC current, DC voltage, active power and reactive power of VSC1

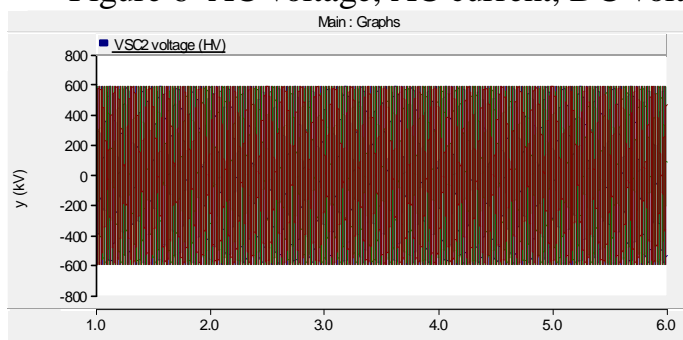

a) $\mathrm{AC}$ voltage

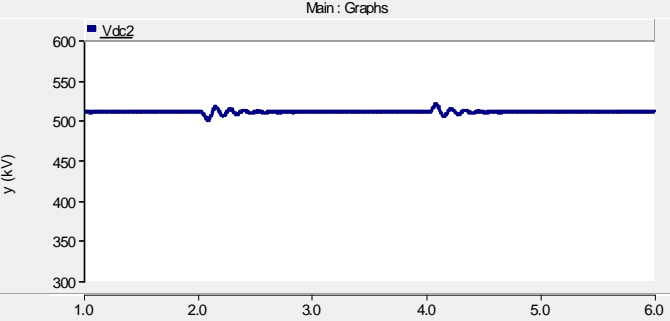

c) DC voltage

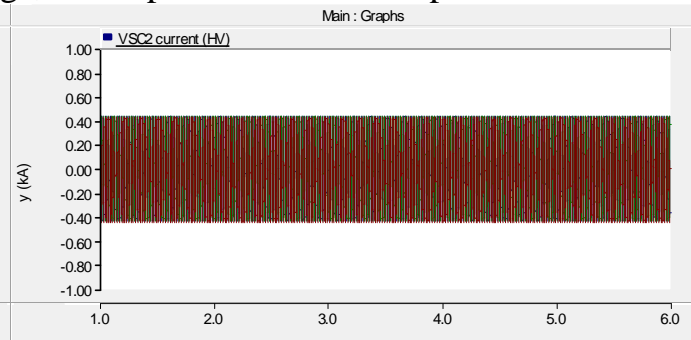

b) $\mathrm{AC}$ current

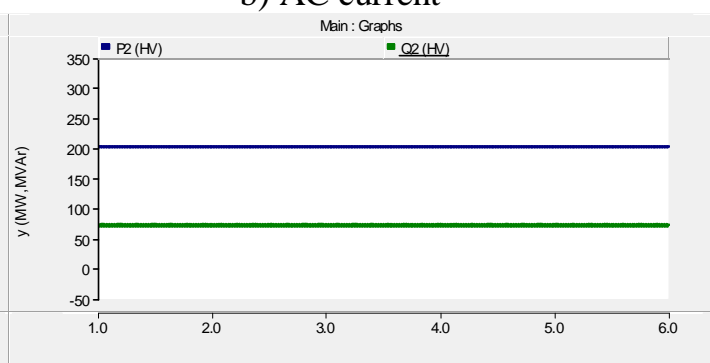

d) Active power and reactive power

Figure 7 AC voltage, AC current, DC voltage, active power and reactive power of VSC2

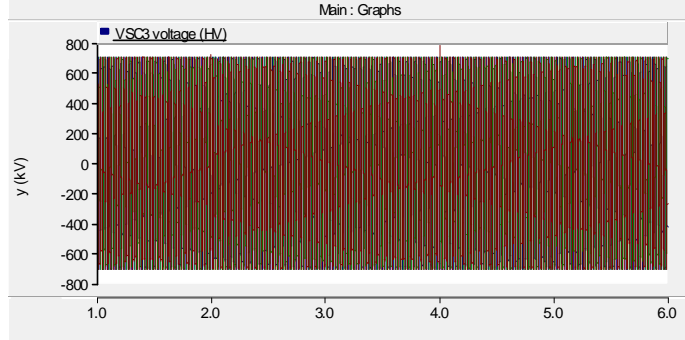

a) $\mathrm{AC}$ voltage

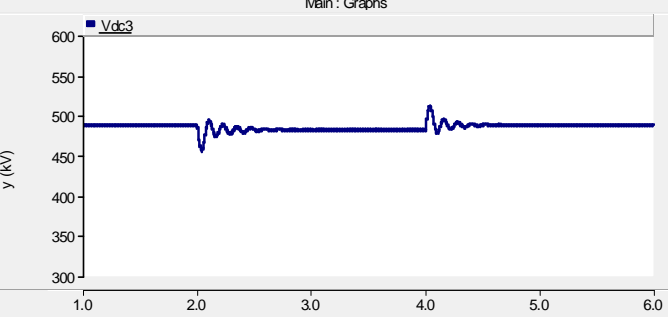

c) $\mathrm{DC}$ voltage

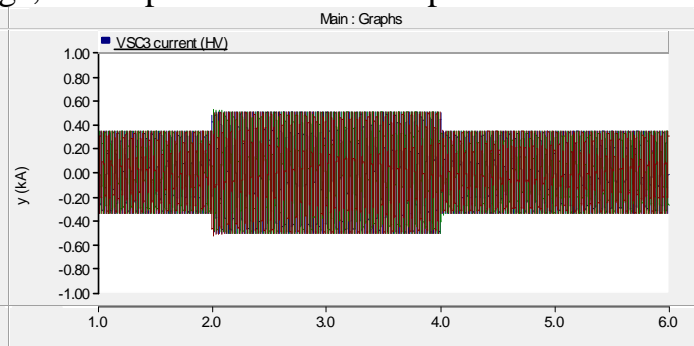

b) AC current Main : Graphs

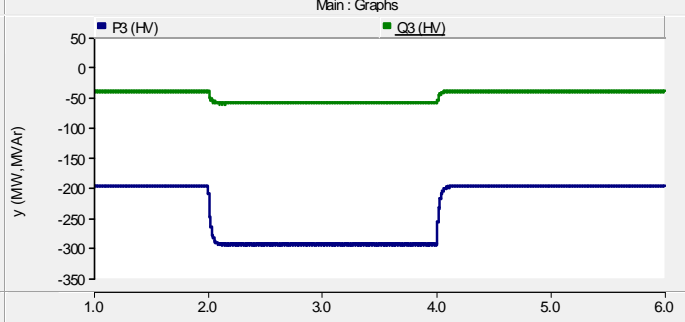

d) Active power and reactive power

Figure 8 AC voltage, AC current, DC voltage, active power and reactive power of VSC3 


\section{Constant load simulation in the faulte state}

(1) Single-phase grounding fault

In the case of phase A grounding fault, the load of VSC3 is 200MW+40MVar (resistance-inductance load). The simulation system enters a steady state after 1s. The AC side of VSC3 occurs phase A grounding fault when the time is $2 \mathrm{~s}$ and the fault is removed after $0.05 \mathrm{~s}$. The VSC1 and VSC2 are normal running. The electrical parameters' change of VSC3 on the AC and DC side are showen in Fig. 9 Fig. 10.

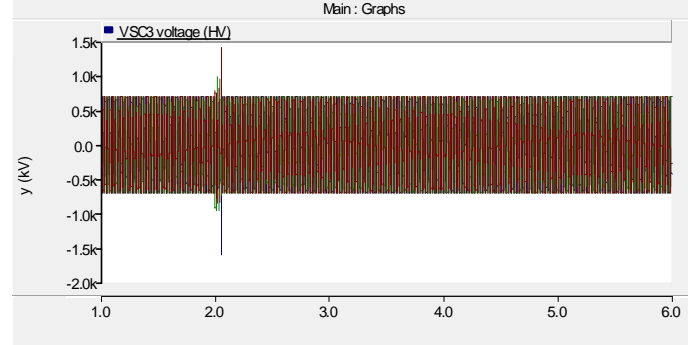

a) AC voltage

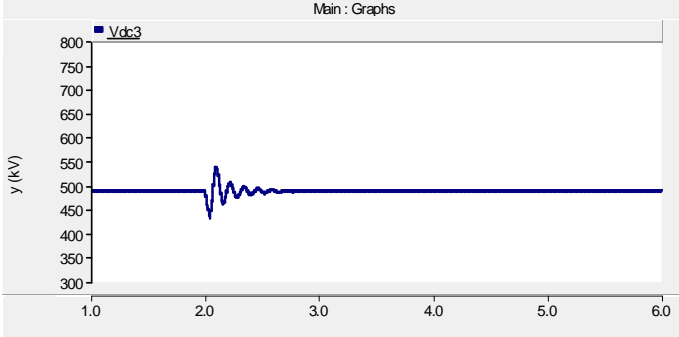

c) DC voltage

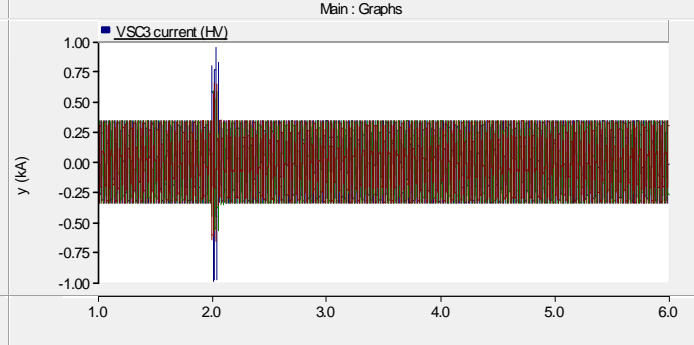

b) $\mathrm{AC}$ current

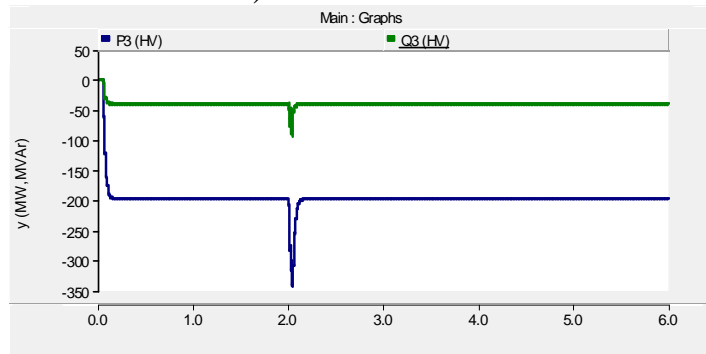

d) Active power and reactive power

Figure 9 AC voltage, AC current, DC voltage, active power and reactive power of VSC3

(2) Three-phase short-circuit fault

The load of VSC3 is 200MW+40MVar (resistance-inductance load). The simulation system enters a steady state after 1s. The AC side of VSC3 occurs three-phase short-circuit fault when the time is $2 \mathrm{~s}$ and the fault is removed after $0.05 \mathrm{~s}$. The VSC1 and VSC2 are normal running. The electrical parameters' change of VSC3 in the AC and DC side are showen in Fig.10.

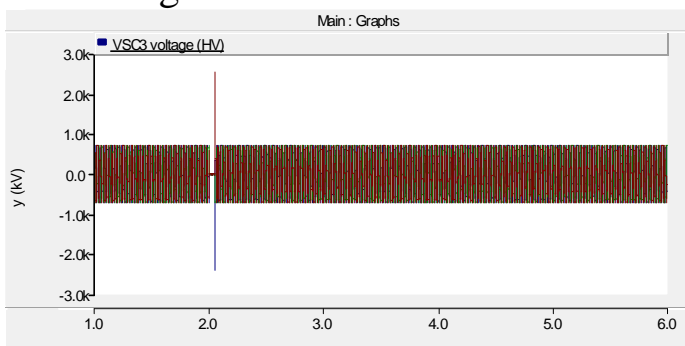

a) $\mathrm{AC}$ voltage

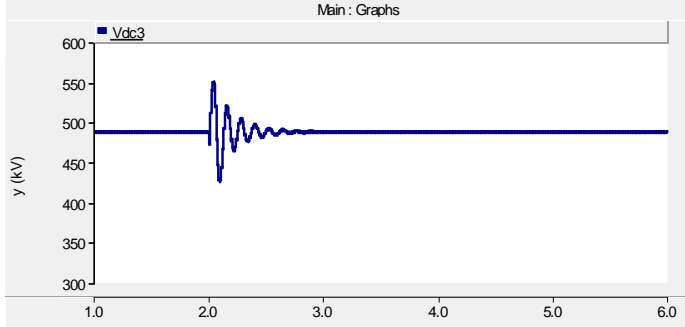

c) DC voltage

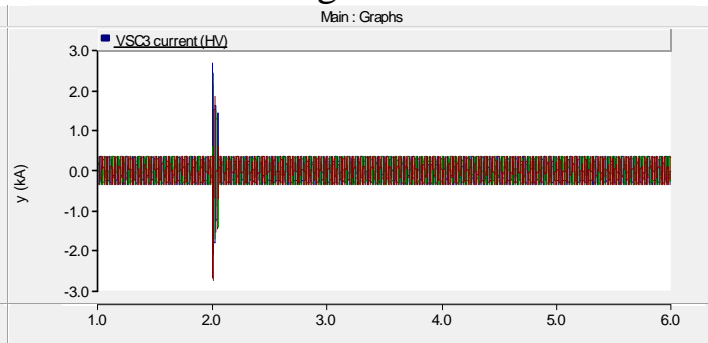

b) AC current Main: Graphs

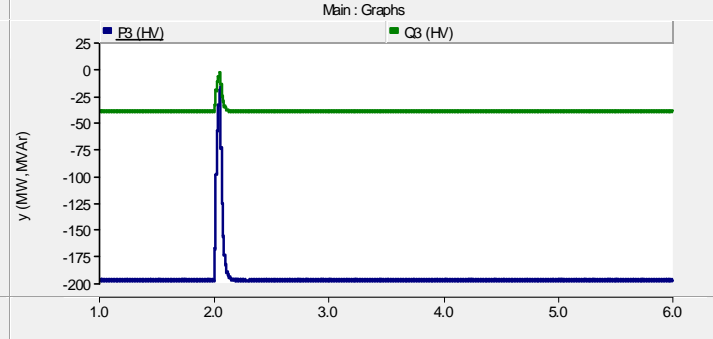

d) Active power and reactive power

Figure 10 AC voltage, AC current, DC voltage, active power and reactive power of VSC3

\section{Analysis of simulation results}

In Fig. $6 \sim$ Fig. 8, when the load of VSC3 which connects to passive power gird increases, the AC voltage is basically unchanged, the AC current increases instantly and enter steady state, and DC voltage just fluctuates slightly. The AC voltage, AC current, active power and reactive power of VSC2 are basically unchanged and the DC voltage just occurs slight fluctuation. The AC voltage of VSC1 is 
basically unchanged. The AC current, active power and reactive power gradually increase and enter steady state. And the DC voltage just occurs slight fluctuation. However, when the load of VSC3, the $\mathrm{AC}$ voltage is basically unchanged, the $\mathrm{AC}$ current decreases instantly and enter steady state and DC voltage just fluctuates slightly. The AC voltage, AC current, active power and reactive power of VSC2 are basically unchanged and the DC voltage just occurs slight fluctuation. The AC voltage of VSC1 is basically unchanged. The AC current, active power and reactive power gradually decrease and enter steady state. And the DC voltage just occurs slight fluctuation. Therefore, the variable load of passive power gird does not influence the distributed generation which adopts constant active power control and constant reactive power control, and it can output power reliably. The load variation can be balanced by the bulk power grid.

When there is a short-circuit fault on the VSC3 side., VSC2 can run normally and the DC voltage just fluctuates slightly. So it is concluded that the passive power grid and distributed generation are independent of each other. The distributed generation can meet the requirements of power generation when there is something wrong with passive power grid. It can be seen from Fig. $9 \sim$ Fig. 10, that when there is a three-phase short-circuit fault, the fluctuations of the AC voltage amplitude, AC current amplitude and DC voltage are much more severe than when the single-phase grounding fault occurs. And it may cause converter station to be abnormal and even menace the security of bulk power system and distributed generation. So protection measures should be introduced to control system of the multi-terminal VSC-HVDC system, and the passive power grid should be removed if necessary, so as not to cause more accidents.

\section{Conclusions}

This paper establishes the model of the three-terminal VSC-HVDC system which contains passive load and distributed generation, and designs the controller of the system. The system with variable load in the steady state and constant load in the faulted state is simulated and analyzed by PSCAD/EMTDC. From the simulation results, it is concluded that: (1) the passive power grid by VSC-HVDC has better voltage control performance and can quickly restore to stability after removal of the fault; (2) multi-terminal VSC-HVDC system has better controllability and independence. There is a little influence between different terminals; (3) the VSC-HVDC technology can control various electrical parameters ideally. It has good prospects for application to the absorption of distributed generation and power supply to the passive power grid region.

\section{Acknowledgements}

This work was financially supported by National Natural Science Foundation (51277067) and Central University Foundation (2015XS03).

\section{References}

[1] Flexible HVDC system[M]. Beijing: China Machine Press, 2012.

[2] High-voltage direct current transmission and flexible ac transmission[M]. Beijing: China Electric Power Press, 2010.

[3] LIANG Hai-feng, LI Geng-yin, WANG Song, et al. VSC-HVDC control system framework[J]. Transactions of China Electrotechnical Society, 2009, 24(5):141-147.

[4] CHEN Qian, TANG Guo-qing, HU Ming, et al. Steady-state model and controller design of a VSC-HVDC converter based on dq0-axis[J]. Automation of Electric Power Systems, 2004, 28 (16):61-66.

[5] DIERCKXSENS C, SRIVASTAVA K, REZA M, et al. A distributed DC voltage control method for VSC MTDC systems[J]. Electric Power Systems Research, 2012, 82(1):54-58. 
[6] LATORRE H F, GHANDHARI M, SOEDER L, et al. Active and reactive power control of a VSC-HVDC[J]. Electric Power Systems Research, 2008, 78(10):1756-1763.

[7] ZHANG L, HARNEFORS L, NEE H P, et al. Modeling and control of VSC-HVDC links connected to island systems[J]. IEEE Transactions on Power Systems, 2011, 26 (2):783-793.

[8] ZHENG Rong-jin, YU Xiao-hong, XIONG Wei ,et al. The simulation control research of MTDC transmission system based on VSC[J]. Central China Electric Power, 2011 ,24(2):32-35.

[9] CHEN Hai-rong, XU Zheng. A novel DC voltage control strategy for VSC Based multi-terminal HVDC system[J]. Automation of Electric Power Systems, 2006, 30(19):28-33.

[10] CHEN Hai-rong. Control strategy of VSC based multi-terminal HVDC transmission system[J]. Electric Power Construction, 2011, 32(8):58-63.

[11] LIANG Hai-feng, LI Geng-yin, LI Guang-kai, et al. Simulation study of VSC-HVDC system connected to passive network[J]. Power System Technology, 2005, 29(8):45-50.

[12] YANG Hao, ZHANG Nan, YE Ming-jia, et al. Study of VSC-HVDC connected to passive network discrete model and its control strategies[J]. Power System Protection and Control, 2012, 40(4):37-42.

[13] ZHAO Cheng-yong, MA Guo-peng, LI Guang-kai. Research on characteristics of regulation of VSC-HVDC supplying power to passive network[J]. Journal of North China Electric PowerUniversity. 2008, 35(6):39-43.

[14] SUN Xiao-yun, TONG Xiang-qian, YIN Jun. Simulation analysis and diagnosis on converter fault in VSC-HVDC system[J]. High Voltage Engineering, 2012, 38(6):1383-1390. 